\title{
A method for determining the onset year of intense browsing
}

\author{
RICHARD B. KEIGLEY, MICHAEL R. FRISINA, AND CRAIG FAGER
}

Authors are Ecologist, U.S. Geological Survey, Northern Rocky Mountain Science Center, 632 Coulee Drive, Bozeman, Mont. 59718; Range Coordinator for Montana Fish, Wildlife \& Parks, 1330 West Gold Street, Butte, Mont. 59701; and Wildlife Biologist, Montana Fish, Wildlife \& Parks, 1820 Meadowlark, Butte, Mont. 59701.

\begin{abstract}
A survey based on browsing related architectures indicated that browsing level had increased at the Mt. Haggin Wildlife Management Area. We describe a technique for determining the year in which the increase in browsing level occurred. The technique is based on the analysis of stems old enough to have experienced the early period of light browsing; the onset year of intense browsing was determined by using dendrochronology to date the formation of twig clusters produced by intense browsing. Stems from 20 Geyer willow (Salix geyeriana Anderss.) plants were analyzed from each of 6 study sites. Mean onset years at the 6 sites ranged from 1983.1 to 1988.4; the mean onset year for all 6 sites was $1985.4 \pm 0.5 \mathrm{SE}(\mathrm{N}=120)$. The reconstructed history was used to evaluate the relationship between moose (Alces alces) number and browse trend. From 1976 to 2000, the winter trend census of moose increased from 7 to 56 . The onset of intense browsing in 1985 occurred when 23 moose were counted.
\end{abstract}

Key Words: Alces alces, architecture, browse-use history, moose, ungulate, willow

A browsing history describes levels of browsing that existed over time. Such histories have many management applications. For example, a browsing history has contributed to philosophical discussions on "what is natural" in Yellowstone National Park (YNP) (Despain et al. 1986, Kay and Wagner 1994, Keigley and Wagner 1998). Where there is historic information on ungulate population size, a historic browse condition can be associated with the ungulate population size that was present at the time (Keigley 1997b, 1998); the reconstructed history may allow a manager to attribute a historic browse condition to one ungulate species rather than another.

Despite the potential management applications, the widespread use of browsing histories is uncommon. In part, the uncommon use may be due to the relatively youthful state of technique development. As we describe below, the application of different techniques has resulted in the inconsistent reconstruction of browsing histories. In part, uncommon use may arise out of lack of appreciation for the potential management applications.

There are 4 principal sources of information from which to reconstruct browse-use histories: 1) scientific reports that document browse use at different points in time, 2) comparison of photographs taken at different points in time, 3) age structure

The study was funded by the U.S. Geological Survey and by Montana Fish, Wildlife \& Parks. Richard Jachowski (U.S. Geological Survey) and Steve Knapp (Montana Fish, Wildlife \& Parks) reviewed early drafts of the manuscript.

Manuscript accepted 20 Aprl 02.

\section{Resumen}

Un reconocimiento basado en arquitecturas relacionadas de ramoneo indicó que el nivel de ramoneo en el Area de Manejo de Fauna Silvestre Mt. Haggin ha aumentado. Describimos las técnicas para determinar el año en el que ocurrió el nivel de ramoneo aumento. La técnica es basada en el análisis de los tallos lo suficientemente viejos para haber experimentado el periodo inicial del ramoneo ligero; el año inicial del ramoneo intenso se determino usando la dendrocronología para determinar la fecha de formación de los racimos de ramas producidas por el ramoneo intenso. Se analizaron tallos de 20 plantas de "Geyer willow" (Salix geyeriana Anderss.) colectadas en cada uno de los 6 sitios de estudio. La media de los años iniciales en los 6 sitios varió de 1983.1 a 1988.4; la media del año final para todos los sitios fue 1985.4 $\pm 0.5 \mathrm{SE}(\mathrm{N}=120)$. La historia reconstruida se uso para evaluar la relación entre el número de Alces (alces) y la tendencia de ramoneo. De 1976 al 2000, la tendencia invernal del censo de alces se incremento de 7 a 56 . El inicio del ramoneo intensivo en 1985 ocurrió cuando se contaron 23 alces.

analysis, and 4) the analysis of browsing-related architectures. Browse-use histories typically draw on a combination of sources. For example, Houston (1982) reconstructed a browse-use history of the northern elk winter range of YNP based on scientific reports and the comparison of historic photographs with morerecent photographs. Kay (1990) reconstructed a browse-use history of aspen (Populus tremuloides Michx.) based on scientific reports, photographs, and age structure analysis. Working in the same area as Houston and Kay, Romme et al. (1995) and Ripple et al. (2001) reconstructed a browsing history of aspen based on age structure. Keigley (1998) reconstructed a browse-use history of a cottonwood stand (Populus angustifolia James) on the YNP northern range based on the dendrochronologic analysis of browsing related architectures. An architecture-based browse-use history of a second YNP cottonwood stand was reconstructed using a combination of height and age data (Keigley 1997b).

Browsing-related scientific reports describe firsthand accounts of browse use. In the Yellowstone National Park (YNP) reports over the period 1935-1957 primarily include descriptions of the effect of browsing on growth form and mortality; beginning in 1958, areal distribution and plant height were measured (unpublished data, YNP). The use of reports for history reconstruction is limited to locations for which information was recorded. In an area such as YNP, much information is available, but in many areas, browse-related studies were not conducted historically.

A comparison of photographs taken at different points in time provides a visual perspective of browse use. As in the case of sci- 
entific reports, the use of photographs is limited to sites for which they are available. The interpretation of historic photographs is subjective, and as a result, interpretations may vary. For example, in an examination of early photographs taken in YNP, Houston (1982) found that conifers were highlined, indicating that intense browsing had occurred since the earliest EuroAmerican presence. In an examination of the same photographs, Kay and Wagner (1994) found that conifers were not highlined indicating that, prior to the establishment of YNP in 1872, browsing was light.

While reports and photographs provide a perspective on gross historic changes, neither source of information provides the resolution of data with which to reconstruct a year-by-year history of browse use. To accomplish this requires the ability to document the year-by-year state of a parameter over an extended period. One parameter in common use is the growth of an aspen stem to breast height. Based on the assumption that growth to breast height corresponds to a year of light browsing pressure, browsing histories are reconstructed by describing the age classes of stems that are present at a site (e.g., Kay 1990, Romme et al. 1995, Ripple et al. 2001).

In an age-structure-based history reconstruction, growth to breast height is a tangible form of evidence, while the evidence for intense browsing is intangible (i.e., intense browsing is inferred from the absence of an age class). The intangible nature of this evidence can lead to difficulties in 2 ways. First, evidence of growth may be missed. Based on the absence of older age-class aspen, Romme et al. (1995) concluded that aspen were intensely browsed prior to the 1870s. In a further examination of YNP aspen, Ripple et al. (2001) discovered evidence for these older age classes, leading to an interpretation that aspen was lightly browsed during that period. Even if evidence for the older age classes had not been found, the significance of that absence would be uncertain because factors unrelated to browsing may have been responsible for the lack of recruitment.

Architectural analysis is the process of reconstructing past browsing conditions based on the dendrochronologic dating of morphologic features; some features are produced by light browsing, others by intense browsing (Keigley 1997a, Keigley and Frisina 1998). The morphologic features provide tangible evidence of both light and intense levels of browsing that occurred in the past (Keigley 1997b, 1998).
We describe a method for reconstructing a history of browsing applicable to sites where browsing pressure has increased from a light-to-moderate level to an intense level. We describe how, during a preliminary reconnaissance, a manager can use gross architectural evidence to identify the condition that browsing intensity increased at some time in the past. We then describe methods for determining the year in which the increase occurred. The paper also describes an application of that reconstructed history.

\section{Materials and Methods}

\section{Study Area}

The study took place on a portion of the 22,743-ha Mt. Haggin Wildlife Management Area located in southwest Montana about $19 \mathrm{~km}$ south of the town Anaconda $\left(45^{\circ} 58^{\prime} \mathrm{N}, 113^{\circ} 4^{\prime} \mathrm{W}\right)$. The study area consists of a combination of wet and dry meadows. Willows (Salix spp.) are common along numerous stream courses and in wide riparian areas created by beaver dams. Elevation of the study area is about 1900 meters; annual precipitation is about $51 \mathrm{~cm}$ (Frisina 1992).

Prior to 1976 , the area was privately owned (Newell and Ellis 1982). Domestic livestock grazed pastures continuously and intensively; willow was sprayed, dozerpiled, and burned to create more grassland for livestock. In 1976, the Montana Fish,

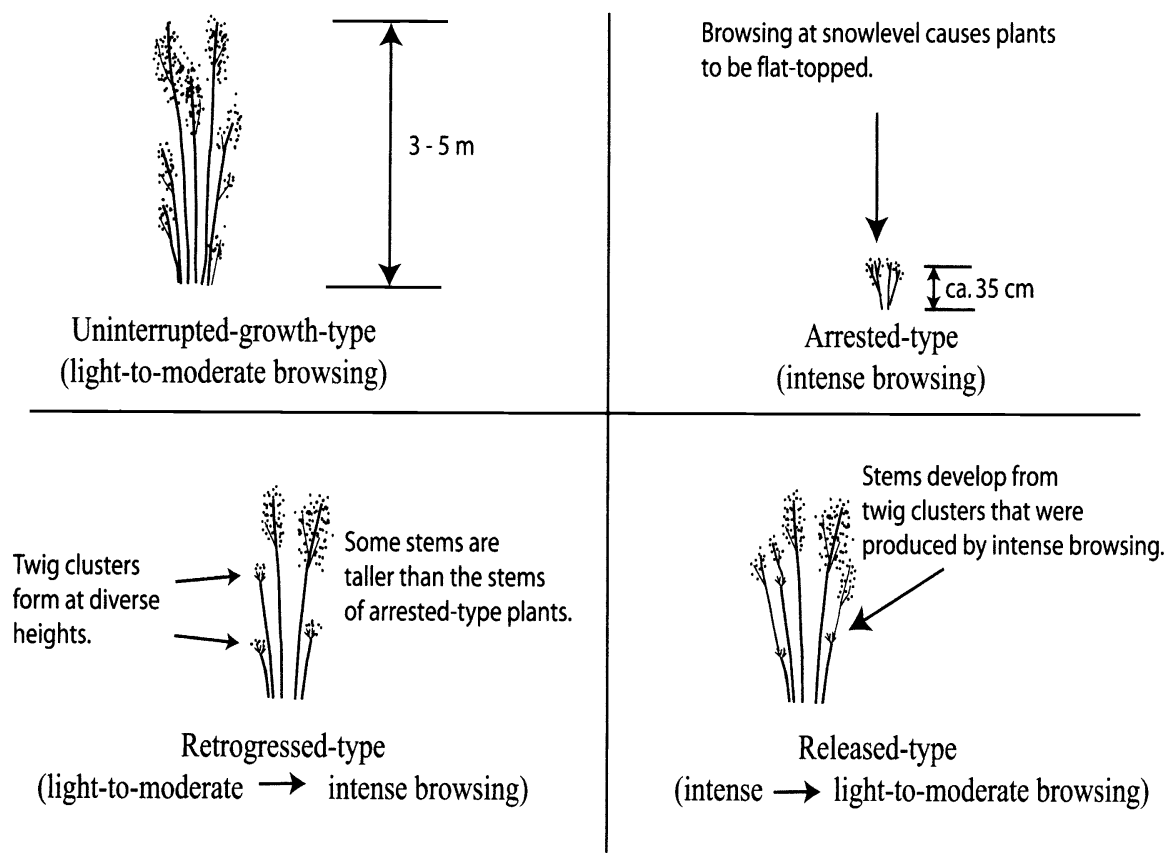

Fig. 1. Four architecture types that are produced by 4 browsing regimes. The architectures are produced during the time that the terminal leader grows within the browse zone.
Wildlife \& Parks (MFWP) purchased the land and established Mt. Haggin Wildlife Management Area to provide habitat for wildlife and public recreational opportunities (Frisina 1982). The reduction of willow stopped. Populations of moose (Alces alces L.), elk (Cervus elaphus L.), mule deer (Odocoileus hemionus Merriam), and pronghorn antelope (Antilocapra americana Ord) increased (Frisina 1982, Kuntz 1993). Recently, whitetail deer (Odocoileus virginianus Merriam) began using the study area during the summer.

Moose are the only large ungulate present on the study area during winter; they concentrate in willow bottoms as snow accumulates. Deer, elk, and antelope inhabit the area during snow-free months, when herbaceous plants are generally preferred and all habitat types are available for foraging. After establishment of the wildlife management area, livestock numbers were reduced (Frisina 1992). A restrotation grazing system was established in 1984 , in which cattle are allowed access to a pasture during the growing season once every third year. Under the new grazing system, livestock were excluded from a 30 ha area; since that time, this area has only been used by wildlife.

\section{Detecting an increase in browsing pressure}

Keigley and Frisina (1998) distinguish between 2 browsing levels: a) light-tomoderate, and b) intense. Light-to-moder- 


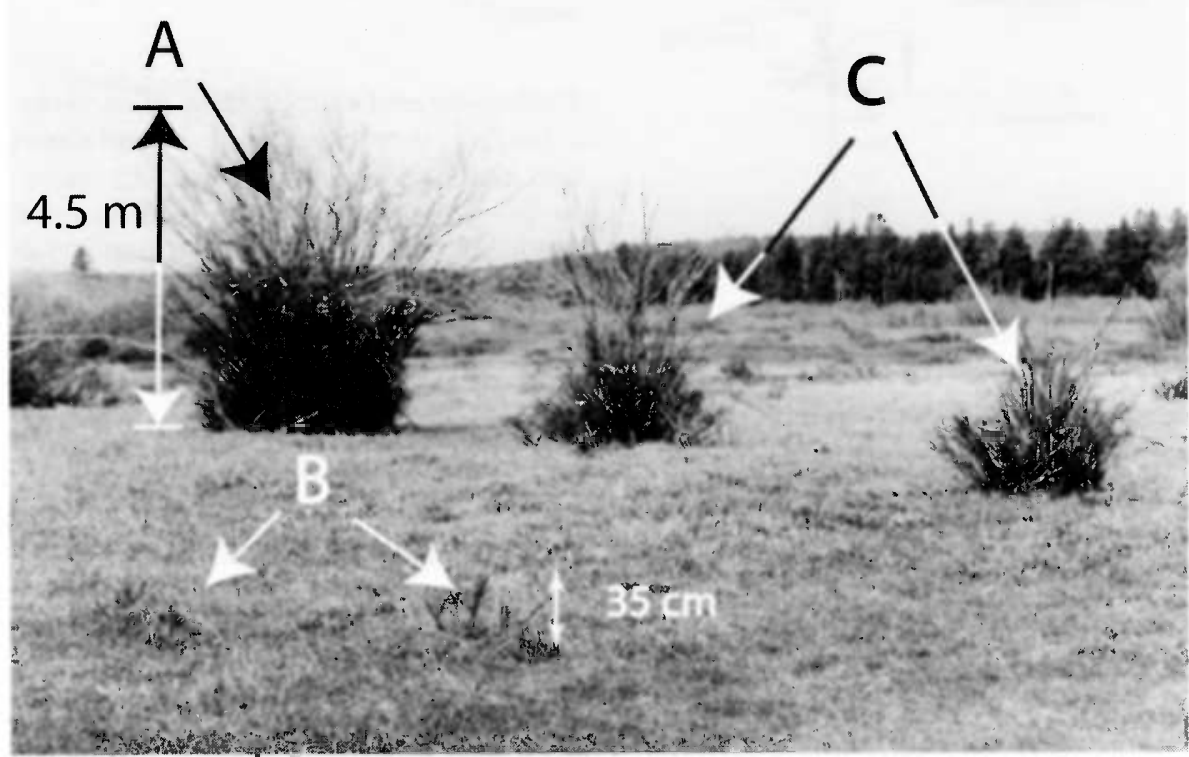

Fig. 2. Older willow plants (A) have grown to heights of $4.5 \mathrm{~m}$ tall, while the youngest plants (B) are browsed to within $35 \mathrm{~cm}$ above ground level. The ability of the older plants to grow taller than $35 \mathrm{~cm}$ indicates that browsing was less intense in the past. At the time browsing level increased, many stems on plant A were out of ungulate reach. The stems of plants of intermediate age $(\mathrm{C})$ were browsed at the height present at the time the increase in browsing pressure occurred. Plants $\mathrm{A}$ and $\mathrm{C}$ have retrogressed-type architecture; plant $\mathrm{B}$ has arrested-type architecture.

ate browsing is defined to occur when current-year-growth develops from the previous-year's-growth. Intense browsing is defined to occur when browsing causes the death of a complete annual segment. In this case, current-year-growth develops from a segment that is older than the previous-year's-growth.

At the whole-plant level, the effect of browsing is expressed in the form of 4 general types of architectures (Fig. 1). The architectures are produced during the period of time that the terminal leader is exposed to browsing. The 4 architecturetypes correspond with 4 browsing regimes:

1) Uninterrupted-growth-type architecture is produced by light-to-moderate browsing as the terminal leader grows through the browse zone.

2) Arrested-type architecture is produced by intense browsing since establishment.

3 ) Retrogressed-type architecture is produced by a change from light-to-moderate browsing to intense browsing.

4) Released-type architecture is produced by a change from intense browsing to light-to-moderate browsing.

In general, similar-aged plants of the same species and site should have experienced a similar level of browsing over their lifetime, and should have the same architecture. On sites where browsing pressure has changed, plants of different age may have different architectures; those architectures should express a similar history. For example, at a site where browsing pressure has increased from light-tomoderate to intense, one might find older retrogressed-type plants and younger arrested-type plants. Given the difference in plant ages, both architectures are consistent with an increase in browsing pressure. At Mt. Haggin, the relationship between willow age and architecture indicated such a history (Fig. 2). The objective of this study was to determine the year in which the increase occurred.

Geyer willow (Salix geyeriana Anderss.) is widely distributed and is substantially used by ungulates at Mt. Haggin. We stratified segments of Deep Creek, Sullivan Creek, and Dry Creek into 6 sample sites; the sites were distributed along a total distance of $3 \mathrm{~km}$. Using the methods described below, we determined the onset year of intense browsing of Geyer willow for each of the six, 0.2 ha sample sites.

\section{Determining the onset year of intense browsing \\ Overview}

The stem morphology produced by light-to-moderate browsing is distinctly different from the morphology produced by intense browsing. Stems that have experienced an increase in browsing level would have the light-to-moderate browsing morphology at the base (where the stem first elongated) and intense-browsing morphology at the distal end. Using dendrochronology, we determined the year in which those morphologic changes occurred.

The stem morphologies are produced as follows. The annual segments of a lightto-moderately browsed stem develop from stem segments produced during the previous year. The new segment may develop either from the previous-year's terminal bud or, if that bud aborted, from lateral buds slightly lower down the stem. Ungulates typically consume segments produced the most recent growing season (current-year-growth). The browsing removes the terminal bud insuring that, if subsequent growth occurs, it must arise by activation of a lateral bud. The stem dies between the point where it was bitten and the point where new growth emerges the following growing season. If ungulates repeatedly consume a minor portion of each year's current-year-growth, the stem grows in a zigzag manner, with dead stubs located at intervals on the stem.

Under heavy browsing pressure, ungulates consume major portions of currentyear-growth, leaving behind a stub of the current annual segment. Because the dead stub is tough and unpalatable, it mechanically protects stems that may subsequently grow beneath it. If ungulates repeatedly browse current-year-growth to a point even with the dead stubs from preceding years, a compact cluster of twigs develops (Fig. 3). Browsed twigs are abruptly terminated by bite marks that are easily distinguishable from other sources of disturbance such as disease or insect infestation. A compact cluster of twigs with bite marks is morphologic evidence of intense browsing. We used dendrochronology to determine the year in which twig clusters formed.

\section{Determining the year of twig cluster for- mation}

The dendrochronologic dating of morphologic features involves determining the year in which a given stem segment was a terminal leader. For a stem segment collected from the beginning of a growing season through the end of the calendar year, the formula for determining the year of initial elongation is:

$$
\mathrm{Y}_{\mathrm{E}}=\text { Collection year }-\mathrm{A}+1 \text {, }
$$

where $Y_{E}$ is the year that the stem elongated and $\mathrm{A}$ is the number of annual rings in 

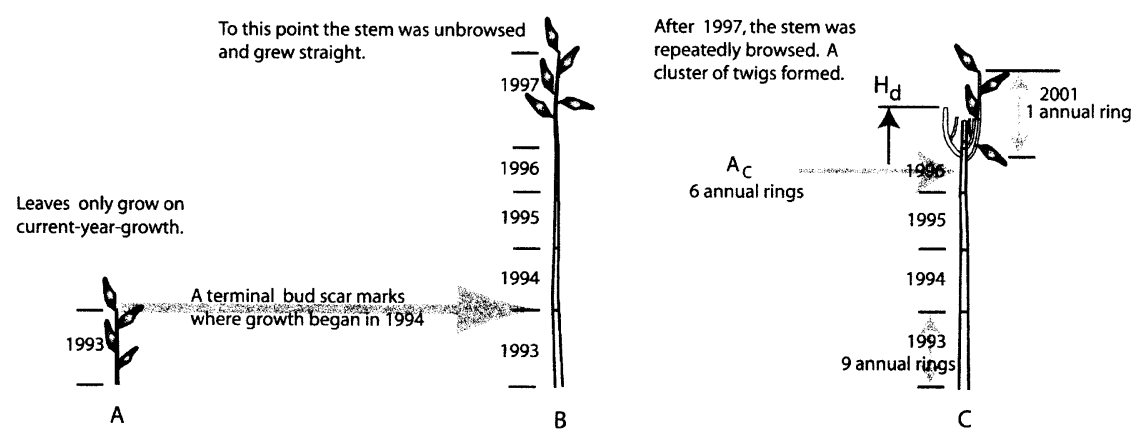

Fig. 3. Stem with live twig cluster. The year of browsing can be directly determined. Stems $A$, B, and $C$ show how plant would appear in during the growing seasons of 1993, 1997, and 2000 , respectively.

the stem segment. For example, a currentyear-growth segment collected in August 2001 would have a single annual ring. The year of elongation is:

$$
\mathrm{Y}_{\mathrm{E}}=2001-1+1=2001 \text {. }
$$

The +1 corrects for the annual ring produced during the current calendar year. If the segment had 9 annual rings, $\mathrm{Y}_{\mathrm{E}}$ would equal 1993. To determine the year of elongation when the stem segment is collected the next calendar year, but before the growing season (e.g., in February), the +1 correction would not be made. The stem segment must be live at the time of collection.

Stem C in Fig. 3 records 2 periods: a period of light-to-moderate browsing (in which the lower stem grew straight) and a period of intense browsing (in which the cluster of twigs formed). Using the formula above, the number of annual rings just below the twig cluster $\left(\mathrm{A}_{\mathrm{C}}\right)$ can be used to determine the last year in which the terminal leader grew under light-to-moderate browsing $\left(\mathrm{Y}_{\mathrm{C}}=\right.$ Collection year $-\mathrm{A}_{\mathrm{C}}+$ 1). Because the stem at point $A_{C}$ is live (and by our definition, light-to-moderately browsed), we assume that intense browsing began the following year $\left(\mathrm{Y}_{\mathrm{I}}=\mathrm{Y}_{\mathrm{C}}+\right.$ 1). To use this method of dating, the twig cluster must be live; we refer to it below as the "live twig cluster method."

Protracted browsing often causes stem dieback of the original stem, with the development of new terminal leaders from the base of the stem (Fig. 4). Because the base of the twig cluster is dead, the annual rings there cannot be directly associated with a given year. To make that association, one must link the dead twig cluster to a live segment of the stem. The onset year of intense browsing is determined from 3 sections:

1. Section $L$ from the primary stem just below the point where the live secondary stem originates. The year that this stem segment was a terminal leader is determined from the number of annual rings. Ring development in section L may be asymmetrical depending on how close the section is to the dead primary stem above it; when counting annual rings, care must be taken to include those produced during the most recent growing season.

2. Section DB from the dead primary stem immediately above the point where the live secondary stem originates. An assumption is made that the stem at point $\mathrm{DB}$ was a terminal leader the same year as at point $\mathrm{L}$. When making collections, the length between points $\mathrm{L}$ and $\mathrm{DB}$ was typically $2-5 \mathrm{~cm}$, so it is likely that the sections were produced the same growing season.

3. Section DC from the base of the dead twig cluster. The difference in the number of annual rings in sections DB and DC indicates the number of years it took for the stem to grow to the base of the cluster. It is assumed that cluster formation began the following year.

The year of twig cluster formation is calculated as follows:

$\mathrm{Y}_{\mathrm{I}}=\left[\right.$ Collection year $\left.-\mathrm{A}_{\mathrm{L}}+1\right]+$

$\left[\mathrm{A}_{\mathrm{DB}}-\mathrm{A}_{\mathrm{DC}}\right]+1$.

The first bracketed term indicates the year that the linking section was a terminal leader; $A_{L}$ is the number of annual rings in the linking segment. As above, +1 may or may not be added depending on when the collection was made. The second term, $\left[A_{D B}-A_{D C}\right]$, indicates the number of years it took the stem to grow to the base of the cluster. The first 2 terms added together indicate the year that the stem at the base of the cluster was a terminal leader. As above, the second +1 is added because browsing intensity is assumed to have increased the year after the stem grew to point DC. Below we refer to this method of dating as the "linked segment method."

\section{Collection and examination of sections}

Sections were collected with hand shears and examined under a dissecting microscope. Sections of live segments were not sanded; sanding of soft (moist) wood tended to collapse the vessel walls, obscuring the view. In cases where the annual rings were not clear, a thin slice was removed with a razor blade. Sections of dry, dead segments were sanded; the view was clarified with a razor as necessary.

\section{Selection of stems for dating}

We determined the onset year of intense browsing from 20 Geyer willow stems at each of the 6 study sites. Each stem was collected from a different shrub.

At sites where browsing level increases from light-to-moderate to intense, all shrubs will eventually have either arrestedor retrogressed-type architecture. Plants with arrested-type architecture may be established after the increase occurred. The dating of twig cluster formation on such plants would indicate a time subsequent to that establishment, not when the initial area-wide increase in browsing occurred. The year of the area-wide increase is only recorded in stems old enough to have experienced both the early period of lightto-moderate browsing and the subsequent period of intense browsing. Such stems are found on retrogressed-type plants.

With respect to suitability for dating, retrogressed-type shrubs can be placed in 2 categories. In one category are retrogressed-type plants that, at the time browsing level increased, had stems that were tall enough to escape ungulate browsing (ca 2.5); these tall stems would not develop morphologic evidence of the increased browsing. After browsing increased, such shrubs would continue to produce stems, some of which would be mechanically protected from browsing within the interior of the shrub. Stems that were within ungulate reach at the time browsing increased would develop twig clusters indicative of the onset year. However, stems that have been mechanically protected within the interior of the shrub may elongate beyond mechanical protection and develop twig clusters. These clusters would not indicate the onset year. Because there is no sure way to distinguish between those possibilities, we avoided this category of retrogressed-type plant.

The second category of retrogressed-type plants consist of those whose tallest termi- 


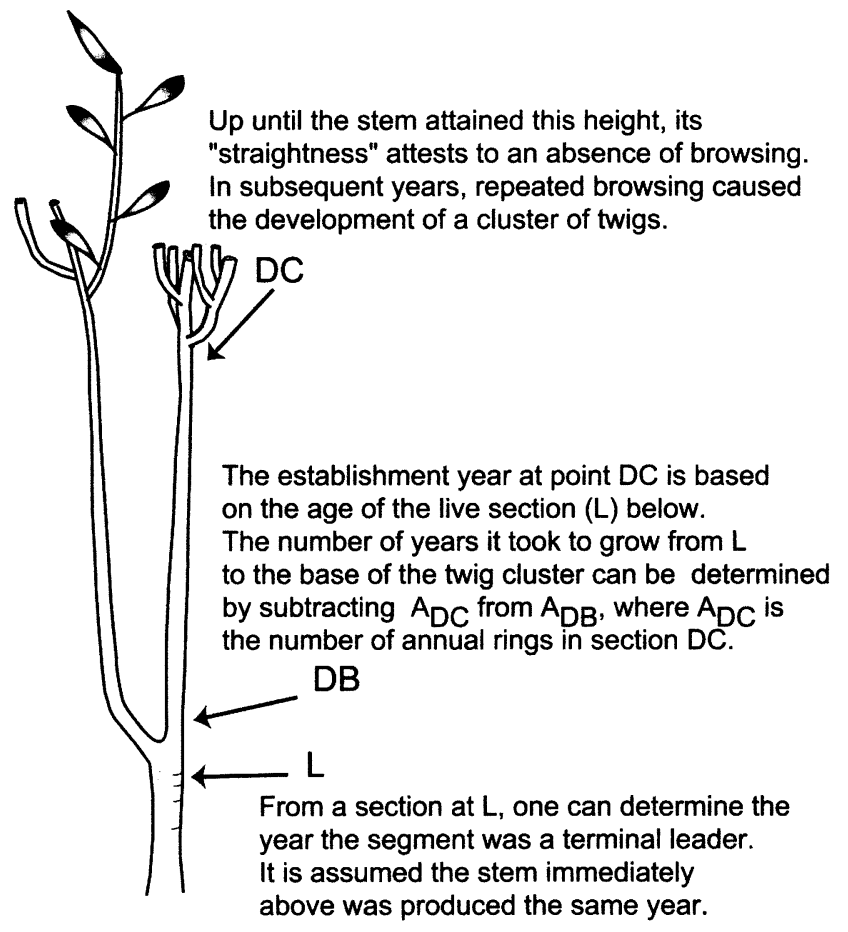

Fig. 4. Stem in which dieback has occurred; the initial twig cluster is dead. To determine the initial year of browsing, the dead twig cluster must be linked to a live stem segment.

nal leaders were within the browse zone at the time browsing increased. When possible, we selected retrogressed-type plants that were $75-200 \mathrm{~cm}$ tall; height was measured to the tip of dead twigs in the cluster $\left(\mathrm{H}_{\mathrm{d}}\right.$ in Fig. 3). The $200 \mathrm{~cm}$ height is well within the reach of moose. We were concerned that plants less than $75 \mathrm{~cm}$ tall might be too young to have experienced the area-wide increase in browsing. Stems within the 75-200 $\mathrm{cm}$ height range were fully exposed to browsing, and were likely old enough to have been present when the area-wide increase occurred. When enough plants within this height range could not be located within the sample area, stems from plants somewhat shorter than $75 \mathrm{~cm}$ were included in the sample.

We sampled the oldest live stem from the selected plant. We assessed stem age in 2 ways. First, we selected stems having large basal girth in comparison to other stems in the shrub. Second, when possible, we selected stems having dead twig clusters. Because protracted browsing kills the upper stem, stems with dead twig clusters are most likely to record the earliest browsing events. The effect of including stems shorter than $75 \mathrm{~cm}$ tall and stems with live twig clusters was analyzed by comparing the results of the full data set with results obtained when plants not meeting the above criteria were removed.

\section{Results and Discussion}

\section{Dating the onset year of intense browsing}

In a preliminary survey we found that all Geyer willow exposed to browsing had either arrested- or retrogressed-type architecture. The lack of uninterrupted-growthtype individuals indicated that the current browsing level was intense. Older Geyer willows had retrogressed-type architecture, while younger plants had arrestedtype architecture (see Fig. 2). This relationship between age and architecture indicates that browsing level has increased. Using the methods described above, we determined that the onset year of intense browsing averaged across sites was 1985.4 \pm 0.5 SE $(\mathrm{N}=120)$ (Table 1).

Table 1. Location of sample sites, year intense browsing began, and lifespan of heavily browsed twigs. $\mathbf{N}=\mathbf{2 0}$.

\begin{tabular}{lcrcc}
\hline \hline Site & $\begin{array}{r}\text { Year intense browsing began } \\
\text { Mean } \pm \text { SE N }=20\end{array}$ & \multicolumn{2}{c}{$\begin{array}{c}\text { Age at base of dead stem } \\
\text { Mean } \pm \text { SE N = 20 }\end{array}$} \\
\hline & & \multicolumn{2}{c}{ (Years) } \\
1 & 1986.9 & \pm 0.7 & 10.6 & \pm 0.5 \\
3 & 1988.4 & \pm 0.9 & 10.2 & \pm 0.7 \\
4 & 1983.1 & \pm 1.5 & 11.4 & \pm 0.8 \\
5 & 1983.7 & \pm 0.9 & 10.1 & \pm 0.5 \\
6 & 1986.9 & \pm 1.1 & 11.5 & \pm 0.7 \\
\hline
\end{tabular}

Effect of including live twig clusters and plants less than $70 \mathrm{~cm}$ tall

For the following reason, we were concerned that the use of live twig clusters might skew the result to a more-recent date. The formation of twig clusters indicates when a stem was first exposed to intense browsing. In the case of the oldest stems, twig cluster formation indicates an area-wide increase in browsing pressure. In the case of younger stems, such as those with live twig clusters, cluster formation may indicate when the stem grew taller than some form of mechanical protection. Out of the total sample of 120,4 dates were obtained from stems with live twig clusters. We examined the effect of including live-twig-cluster data by excluding those data and recalculating a pooled mean. The resulting date was identical: $1985.4 \pm 0.5( \pm \mathrm{SE})$.

The average age of the stem at the base of the dead twig clusters was $10.2 \pm 0.3$ years $( \pm$ SE) (Table 1$)$. This age suggests that live twig clusters may reliably indicate the onset of intense browsing for periods up to about 10 years. To document an onset of browsing that occurred more than 10 years in the past, one should sample stems with dead twig clusters and determine the onset date by the linked segment method.

We were concerned about the potential effect of including plants less than $75 \mathrm{~cm}$ tall. Because the age of the plants was not known at the time of sampling, we were concerned that short plants might be too young to accurately reflect the earliest increase in browsing pressure. We examined the effect of sampling 11 such plants by excluding them from the data set. The resulting mean onset year was $1985.4 \pm$ $0.5 \mathrm{SE}$, a value identical to those above.

\section{Comparison with other methods of history reconstruction}

Architectural analysis and age structure analysis can be used to document past levels of browsing at any site where shrubs of suitable age are present; scientific reports 


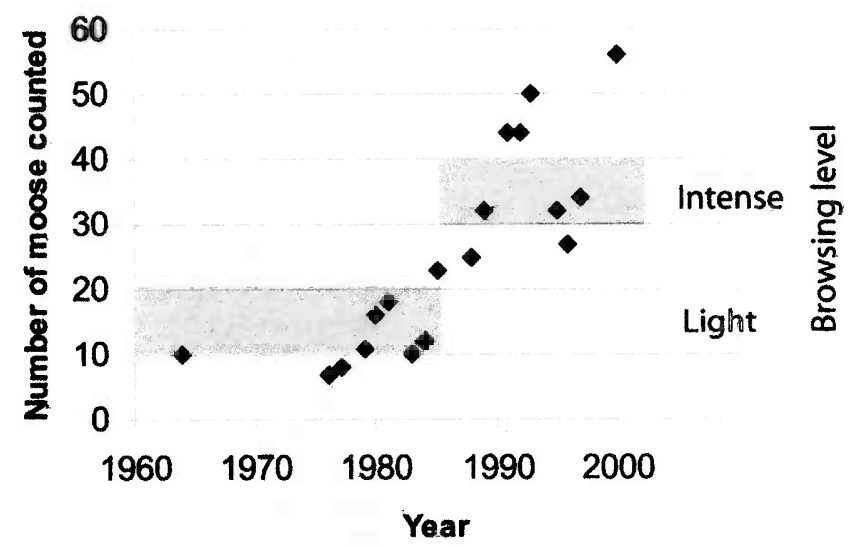

Fig. 5. Relationship between moose census number and browsing intensity. Based on the pooled data, browsing intensity changed from a light-to-moderate level to an intense level in 1985. The horizontal line indicates the range of onset dates that occurred over the 6 study sites.

and photographs can only be used where this information was recorded in the past. Age structure analysis can only document periods of light browsing in which stems grew; because the absence of an age class can be caused by multiple factors, periods of intense browsing and transitions in browsing levels cannot be dated. Architectural analysis dates the transition from a morphology produced by light browsing to a morphology produced by intense browsing; as a result, periods of intense browsing are documented and a history is reconstructed that has fewer gaps.

The technique described above provides a repeatable method of determining a date at a given site. Because ungulates prefer some browse species over others, the date applies only to the browse species on which it was based. By measuring the onset dates of other species, one can examine interspecific patterns of browse use.

\section{An application of the reconstructed history}

The study area lies within Montana Fish, Wildlife and Parks (MFWP) moose Hunting District 325. Moose population data collected during winter aerial surveys of Hunting District 325 from 1964 through 2000 were used to determine population trend (Fig. 5). In any census, the data represent the actual number of moose observed; the total number of moose in the population is greater (Anderson and Lindzey 1996). We view the census data as an index of trend.

Three lines of evidence indicate that moose are primarily responsible for the recent impacts on browse plants. First, heavy browsing occurs at a site where livestock have been excluded since 1984 (Site 1). Browsing within this 30 ha area must have been due to wild ungulates. Second, the average onset years for intense browsing (1983-1988) coincide with the period in which the HD 325 moose population was increasing most dramatically. During this period, a grazing system was established that lessened the impact of livestock (Frisina 1992). Third, because of mid-winter snow conditions, moose are the only ungulate to occupy the area year-round. These factors suggest that moose played an important role at all 6 sites.

The lack of willow with uninterruptedgrowth type architecture suggests that the willow carr is in the process of conversion to a meadow-like condition. The fact that this conversion began during period of a moose population increase suggests that, to reverse the trend, the population must be reduced.

The reconstructed history indicates the magnitude of the required reduction. The increase in browsing pressure first occurred in 1983 (at Site 3) when 10 moose were counted. The latest year to mark the increase in browsing was 1988 (at Site 2) when 25 moose were counted. In the mean onset year of 1985, 23 moose were counted. We conclude that, to reverse the trend to a meadow-like condition, the moose population must be reduced by about half. In 2000 , the moose harvest quota was increased by $50 \%$. A monitoring program has been instituted to determine the effect of moose reductions.

\section{Literature Cited}

Anderson, C. R. Jr. and F. G. Lindzey. 1996. Moose sightability model developed from helicopter surveys. Wildl. Soc. Bull. 24(2): $247-259$.
Despain, D., D. Houston, M. Meagher, and P. Schullery. 1986. Wildlife in transition: man and nature on Yellowstone's northern range. Roberts Rinehart, Boulder, Colo.

Frisina, M. 1982. Mount Haggin: Management Plans. Montana Outdoors. May/June 1982: 31-33.

Frisina, M. R. 1992. Elk habitat use within a rest-rotation grazing system. Rangelands 14(2): 93-96.

Houston, D.B. 1982. The northern Yellowstone elk: ecology and management. MacMillan Publishing Company, Inc., New York, N.Y. $474 \mathrm{pp}$.

Kay, C.E. 1990. Yellowstone's northern elk herd: A critical evaluation of the "natural regulation" paradigm. Diss., Utah State Univ., Logan, Utah. $490 \mathrm{pp}$

Kay, C.E. and F.H. Wagner. 1994. Historical condition of woody vegetation on Yellowstone's northern range: A critical evaluation of the natural regulation paradigm, pp. 151-169. In: D. Despain, ed. Plants and their environments: proceedings of the first scientific conference on the Greater Yellowstone Ecosystem. Tech. Rep. NPS/NRYELL/NRTR USDI, NPS, Denver, Colo.

Keigley, R.B. 1997a. A growth form method for describing browse condition. Rangelands 19:26-29.

Keigley, R.B. 1997b. An increase in herbivory of cottonwood in Yellowstone National Park. Northwest Sci. 71:127-136.

Keigley, R.B. 1998. Architecture of cottonwood as an index of browsing history in Yellowstone. Intermountain J. Sci. 4:57-67.

Keigley, R.B. and M.R. Frisina. 1998. Browse evaluation by analysis of growth form. Montana Fish, Wild., and Parks. Helena, Mont. $149 \mathrm{pp}$.

Keigley, R.B. and F.H. Wagner. 1998. What is "natural"?:Yellowstone elk population-a case study. Integrative Biol. 1:133-148.

Kuntz, B. 1993. A home where elk and cattle roam. Mount Haggin Wildlife Management Area. Montana Outdoors. March/April 1993. 3 pages.

Newell, A. and D. Ellis. 1982. Mount Haggin: Living History. Montana Outdoors. May/June 1982: 27-31.

Ripple, W.J., E.J. Larsen, R.A. Renkin, and D.W. Smith. 2001. Trophic cascades among wolves, elk, and aspen on Yellowstone National Park's northern range. Biological Cons. 102:227-234.

Romme, W.H., M.G. Turner, L.L. Wallace, and J.S. Walker. 1995. Aspen, elk, and fire in northern Yellowstone National Park. Ecol. 76:2097-2106

Smith, C.L., A.A. Simpson, and V. Bailey. 1915. Report on investigations of the elk herds in the Yellowstone region of Wyoming, Montana, and Idaho. United States Bureau of Biological Survey and USDA Forest Serv. Unpublished report in Yellowstone National Park Archives, Yellowstone National Park, Wyoming. $56 \mathrm{pp}$.

Wright, G.M. and B.H. Thompson. 1935. Wildlife management in the national parks. Fauna of the National Parks No. 2. US Gov. Printing Office. Washington, D.C. 142 pp. 